Pacific Journal of Mathematics

CLOSED LINEAR OPERATORS AND ASSOCIATED 


\title{
CLOSED LINEAR OPERATORS AND ASSOCIATED CONTINUOUS LINEAR OPERATORS
}

\author{
SEYMOUR GoLdBERG
}

Introduction. Suppose $X$ and $Y$ are normed linear spaces. Throughout this paper, $T$ shall be a closed linear operator with domain $D(T)$ dense in $X$ and range $R(T) \subset Y$. For the sake of completeness, we present the classification scheme devised in [7].

As regards $R(T)$, there are the following three possibilities:

I: $R(T)=Y$,

II: $R(T) \neq Y$ but $\overline{R(T)}=Y$,

III: $\overline{R(T)} \neq Y$.

If $R(T)=Y$, we say that $T$ is in state $I$, written $T \in I$. Analogous notation is used regarding II and III.

As regards $T^{-1}$, there are the following there possibilities:

1: $T^{-1}$ exists and is continuous,

2: $T^{-1}$ exists but is not continuous,

3: $T^{-1}$ does not exist.

Here we say that $T$ is in state 1 , written $T \in 1$, to indicate that $T$ has continuous inverse, with analogous usage concerning 2 and 3.

By combining the various possibilities from the two lists, we obtain nine possible states for $T$, e.g., $T \in I_{3}$ shall mean that $R(T)=Y$ and that $T$ has no inverse.

This classification scheme may now be applied to the conjugate $T^{\prime}$ of T. A corresponding "state diagram" was constructed in [3] which exhibits the states which can occur for $T$ together with $T^{\prime}$.

The purpose of this paper is to give some insight into the reasons why the state diagram for closed linear operators is the same as that for continuous linear operators (cf. [3]). It is shown that given $T$ closed, there corresponds a continuous linear operator $T$ such that $T$ and $T^{\prime}$ are in the same states as $T$ and $T^{\prime}$, respectively.

In the sequel, we shall adopt the following convention: if $E$ is a linear space and $\Gamma$ is a set of linear functionals on $E$, then $(E, \Gamma)$ is the set $E$ with the weak topology induced by $\Gamma$ (cf. [2, p. 419]). For any set $K \subset E, \bar{K}^{(E, \Gamma)}$ shall denote the closure of $K$ in $(E, \Gamma)$. The set $I^{\prime}$ will be called total if $f(x)=0$ for all $f \in \Gamma$ implies $x=0$. If $\Gamma$ is a total subspace, then $(E, \Gamma)$ is a locally convex topological linear space which is also Hausdorff.

Definition. Let $D\left(T^{\prime}\right)_{1}$ denote the linear space $D\left(T^{\prime}\right)$ with norm

Received May 23, 1961. This work was sponsored, in part, by the National Science Foundation under grant NSF-G18052. 
defined by $\left\|y^{\prime}\right\|_{1}=\left\|y^{\prime}\right\|+\left\|T^{\prime} y^{\prime}\right\|$. It was noted by Sz.-Nagy [5], that $D\left(T^{\prime}\right)_{1}$ is a Banach space. Define $T_{1}^{\prime}$ as the operator $T^{\prime}$ mapping $D\left(T^{\prime}\right)_{1}$ into $X^{\prime}$.

Theorem 1 shows that, with the appropriate identifications, $D\left(T^{\prime}\right)_{1}$ is not only complete, but is in fact a conjugate space. Moreover, the corresponding operator $T_{1}^{\prime}$ is the conjugate of a bounded linear operator.

The following lemma is due to I. Singer [6, Theorem 1].

Lemma. Let $E$ be a normed linear space, $V$ a subspace of $E^{\prime}$ and $\mathscr{F}$ the "canonical mapping" of $E$ into $V$ ' defined by

$$
[\mathscr{J}(x)] v=v(x) \text { for every } v \in V .
$$

Denote by $S_{E}$ and $S_{V^{\prime}}$ the closed unit spheres in $E$ and $V^{\prime}$, respectively. Then $\mathscr{I} S_{E}$ is dense in $S_{V^{\prime}}$ with respect to the $w^{*}$ topology, $\left(V^{\prime}, V\right)$.

Theorem 1. Define $J: Y \rightarrow\left(D\left(T^{\prime}\right)_{1}\right)^{\prime}$ by $(J y) y^{\prime}=y^{\prime} y$. Let $\mathscr{F}$ : $D\left(T^{\prime}\right)_{1} \rightarrow(J Y)^{\prime}$ be defined by $\left(\mathscr{J} y^{\prime}\right) J y=(J y) y^{\prime}$. Then

(i) $D\left(T^{\prime}\right)_{1}$ is linearly isometric to $(J Y)^{\prime}$ under the map $\mathscr{I}$ and $\left\|y^{\prime}\right\|_{1}=\sup _{\| J y||=1}\left|y^{\prime} y\right|$

(ii) JT is a continuous linear map from normed linear space $D(T)$ into normed linear space JY. Moreover, $T_{1}^{\prime}=(J T)^{\prime} \mathscr{I}$.

(iii) The states of $T$ and $T^{\prime}$ are the same as those of continuous linear operators $J T$ and $(J T)^{\prime}$ respectively.

Proof of (i). For convenience, Let $E$ denote $D\left(T^{\prime}\right)_{1}$ and let $V$ denote $J Y$. Since $\left|(J y) y^{\prime}\right|=\left|y^{\prime} y\right| \leqq\left\|y^{\prime}\right\|_{1}\|y\|$ for all $y^{\prime} \in E$, it follows that $V \subset E^{\prime}$ and $\|J\| \leqq 1$. Obviously $V$ is a total subspace of $E^{\prime}$ and both $\mathscr{J}$ and $J$ are one-to-one. We now prove that the image of $\mathscr{F}$ is $V^{\prime}$. By [4], the closed unit sphere $S_{E}$ in $E$ is a compact subset of ( $\left.Y^{\prime}, Y\right)$, i.e., $Y^{\prime}$ with the $w^{*}$ topology. Since $(E, V)$ is $E$ with the relative topology inherited from $\left(Y^{\prime}, Y\right), S_{E}$ is also a compact subset of $(E, V)$. Thus $S_{E}=\bar{S}^{(E, V)}$ since $(E, V)$ is Hausdorff. It is easy to see that $\mathscr{I}$ is a homeomorphism from $(E, V)$ onto $\mathscr{I} E$ with respect to the relative topology inherited from $\left(V^{\prime}, V\right)$. Hence by the lemma,

$$
\left(^{*}\right) S_{E}=\mathscr{I} \bar{S}_{E}^{(E, V)}=\overline{\mathscr{I} S_{E}^{(E, V)}} \cap \mathscr{F} E=S_{V^{\prime}} \cap \mathscr{F} E \text {. }
$$

Therefore, $S_{V^{\prime}} \cap \mathscr{I} E$ is compact and thus closed in Hausdorff space $\left(V^{\prime}, V\right)$. Suppose that $\mathscr{I} E \neq V^{\prime}$. Then there exists some $v^{\prime} \in V^{\prime}$ such that $\left\|v^{\prime}\right\|=1$ and $v^{\prime} \notin E$, i.e., $v^{\prime}$ is not a member of the convex set $S_{V^{\prime}} \cap \mathscr{J} E$ which we have shown closed in $\left(V^{\prime}, V\right)$. By [2, theorem V. 2.10], there exists a linear functional $f$ which is continuous on $\left(V^{\prime}, V\right)$ and a constant $c$ such that

$$
R f\left(v^{\prime}\right)>c \geqq R f\left(S_{V^{\prime}} \cap \mathscr{I} E\right) .
$$


Thus

$$
\left({ }^{* *}\right) c \geqq \sup _{z^{\prime} \in S_{V}, \cap \mathscr{F}_{E}}\left|f\left(z^{\prime}\right)\right|,
$$

for if $u \in S_{V^{\prime}} \cap \mathscr{F} E$, and $f(u)=|f(u)| e^{i \theta}$, then $e^{-i \theta} u \in S_{V^{\prime}} \cap \mathscr{I} E$. Hence $c \geqq R f\left(e^{-i \theta} u\right)=|f(u)|$. Since $f$ is continuous on $\left(V^{\prime}, V\right)$, it follows from [2, Theorem V. 3.9] that there exists some $v \in V$ such that $f\left(z^{\prime}\right)=z^{\prime}(v)$ for all $z^{\prime} \in V^{\prime}$. Consequently, by $\left({ }^{*}\right)$ and $\left({ }^{* *}\right)$ we infer that

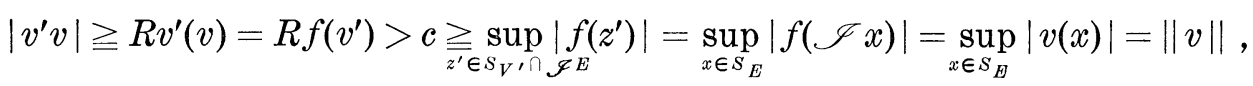

where $\|v\|$ is the norm of $v \in E^{\prime}$. Hence $v^{\prime}(v /\|v\|)>1$. This, however, is a contradiction since $\left\|v^{\prime}\right\|=1$. We have therefore shown that $\mathscr{J}$ must map $E$ onto $V^{\prime}$. Now from $\left({ }^{*}\right), S_{E}=\mathscr{J}^{-1} S_{V^{\prime}}$. Therefore, given any $y^{\prime} \in E$,

$$
\left\|y^{\prime}\right\|_{1}=\left\|\mathscr{F}^{-1} \mathscr{F} y^{\prime}\right\|=\left\|\mathscr{F} y^{\prime}\right\| \leqq\left\|y^{\prime}\right\|_{1}
$$

which shows that $\mathscr{J}$ is an isometry and

$$
\left\|y^{\prime}\right\|_{1}=\left\|\mathscr{J} y^{\prime}\right\|=\sup _{|| J y||=1}\left|\left(\mathscr{F} y^{\prime}\right) J y\right|=\sup _{|| J y||=1}\left|y^{\prime} y\right| \text {. }
$$

REMARK. By examining closely [1, Theorem 19], one can conclude that (i) is valid after observing that $S_{E}$ is compact in $(E, V)$ [4]. The proof given above, however, is quite different from the proof given by Dixmier, and indeed, may be used to prove Theorems 19 and 17' of Dixmer.

Proof of (ii). $J T$ is continuous from $D(T)$ into $E^{\prime}$ since

$$
\text { ||(JTx) } y^{\prime}|=| y^{\prime} T x|=| T^{\prime} y^{\prime} x \mid \leqq\left\|T^{\prime} y^{\prime}\right\|\|x\| \leqq\left\|T_{1}^{\prime}\right\|_{1}\left\|y^{\prime}\right\|_{1}\|x\|
$$

implies that $\|J T\| \leqq\left\|T_{1}^{\prime}\right\|$. For $x$ in $D(T)$ and $y^{\prime}$ in $E$,

$$
\begin{aligned}
{\left[(J T)^{\prime}\left(\mathscr{F} y^{\prime}\right)\right] x } & =\left(\mathscr{F} y^{\prime}\right)(J T x)=(J T x) y^{\prime} \\
& =y^{\prime} T x=T_{1}^{\prime} y^{\prime}(x)=\left[\left(T_{1}^{\prime} \mathscr{I}^{-1}\right)\left(\mathscr{F} y^{\prime}\right)\right] x .
\end{aligned}
$$

Hence $(J T)^{\prime}\left(\mathscr{J} y^{\prime}\right)=T_{1}^{\prime} \mathscr{J}^{-1}\left(\mathscr{J} y^{\prime}\right)$ or $(J T)^{\prime}=T_{1}^{\prime} \mathscr{J}^{-1}$.

From the above result it is obvious that $T_{1}^{\prime}$ and $(J T)^{\prime}$ are in the same state. We assert that $T^{\prime}$ and $T_{1}^{\prime}$ are in the same state and therefore so are $T$ and $(J T)^{\prime}$. It suffices to show that $T^{\prime} \in 1$ if and only if $T_{1}^{\prime} \in 1$. If $T^{\prime} \in 1$, then $T_{1}^{\prime}$ has an inverse and $R\left(T_{1}^{\prime}\right)=R\left(T^{\prime}\right)$ is closed since $T^{\prime}$ is closed. However, $T_{1}^{\prime}$ is a continuous linear operator on Banach space $E$. Therefore, as a consequence of the interior mapping principle, $T_{1}^{\prime} \in 1$. Conversely, if $T_{1}^{\prime} \in 1$, then $T^{\prime}$ has an inverse and $R\left(T^{\prime}\right)$ is closed. By the closed graph theorem, it follows that $T^{\prime} \in 1$. 
It is easy to verify that $T$ and $J T$ are in the same "range state". Finally, to prove that $T$ and $J T$ are in the same state, it remains only to show that $T \in 1$ if and only if $J T \in 1$. By inspecting the state diagram in [3], and recalling that $T^{\prime}$ and $(J T)^{\prime}$ are in the same state, we can conclude that $T \in 1, T^{\prime} \in I$ and $J T \in 1$ are equivalent statements.

2. Let $\overline{J Y}$ be the closure of $J Y$ in $E^{\prime} . \overline{J Y}$ is therefore a Banach space. Suppose $X$ and $Y$ are Banach spaces. Define $\widehat{J T}: X \rightarrow \overline{J Y}$ as the continuous linear extension of $J T$. We now compare the states of $T$ and with those of $\widehat{J T}$ and $(\widehat{J T})^{\prime}$ respectively.

Clearly, $(J T)^{\prime}=(\widehat{J T})^{\prime}$. This implies, by the preceding results, that $T^{\prime}$ and $(\widehat{J T})^{\prime}$ are in the same state. An inspection of the state diagram in [3] verifies the following assertions:

(a) $T \in I$ if and only if $T^{\prime} \in 1$ if and only if $\widehat{J T} \in I$.

(b) $T \in I I$ if and only if $T^{\prime} \in I I_{2}$ or $I I I_{2}$ if and only if $\widehat{J T \in I I}$.

(c) $T \in I I I$ if and only if $\widehat{J T} \in I I I$.

(d) $T \in 1$ if and only if $T^{\prime} \in I$ if and only if $\widehat{J T} \in 1$.

(e) If $X$ is reflexive, then $T \in 2$ if and only if $T \in I I_{2}$ or $I I_{3}$ if and only if $\widehat{J T} \in 2$.

(f) If $X$ reflexive, then $T \in 3$ if and only if $\widehat{J T} \in 3$.

We thus obtain the following

THeOREM 2. Suppose $X$ and $Y$ are complete. Then

(i) The states of $T^{\prime}$ and $(J T)^{\prime}$ are the same.

(ii) T and JT are in the same "range state."

(iii) $T \in 1$ if and only if $\widehat{J T} \in 1$.

(iv) If $X$ is reflexive, then the state diagram for $T$ and $T^{\prime}$ is the same as that for $\widehat{J T}$ and $(\widehat{J T})^{\prime}$.

\section{REFERENCES}

1. J. Dixmier, Un théorème de Banach, Duke Math. J., 15 (1948), 1057-1071.

2. N. Dunford and J. T. Schwartz, Linear Operators, Part I, Interscience Pub., New York.

3. S. Goldberg, Linear operators and their conjugates, Pacific J. Math., 9 (1959), 69-79.

4. J. T. Joichi, On closed operators with closed range, Proc. Amer. Math. Soc., 11 (1) (1960), 80-83.

5. J. Sz.-Nagy, On the stability of the index of unbounded linear transformations, Acta Math, Acad. Sci. Hungar., 3 (1952), 49-52.

6. I. Singer, On a theorem of J. D. Weston, The J. of London Math. Soc., 34 (1959), 320-324.

7. A. E. Taylor and C. J. A. Halberg Jr., General theorems about a linear operator and its conjugate, J. Reine Angew. Math., 198 (1957), 93-111. 


\section{PACIFIC JOURNAL OF MATHEMATICS}

\section{EDITORS}

Ralph S. Phillips

Stanford University

Stanford, California

M. G. Arsove

University of Washington

Seattle 5, Washington
A. L. Whiteman

University of Southern Californla

Los Angeles 7, California

Lowell J. Paige

University of California

Los Angeles 24, California

\section{ASSOCIATE EDITORS}

E. F. BECKENBACH

D. DERRY

H. L. ROYDEN

E. G. STRAUS

T. M. CHERRY

M. OHTSUKA

E. SPANIER

F. WOLF

\section{SUPPORTING INSTITUTIONS}

UNIVERSITY OF BRITISH COLUMBIA

STANFORD UNIVERSITY

CALIFORNIA INSTITUTE OF TECHNOLOGY

UNIVERSITY OF CALIFORNIA

MONTANA STATE UNIVERSITY

UNIVERSITY OF TOKYO

UNIVERSITY OF UTAH

UNIVERSITY OF NEVADA

NEW MEXICO STATE UNIVERSITY

OREGON STATE UNIVERSITY

UNIVERSITY OF OREGON

OSAKA UNIVERSITY

WASHINGTON STATE UNIVERSITY

UNIVERSITY OF WASHINGTON

UNIVERSITY OF SOUTHERN CALIFORNIA

AMERICAN MATHEMATICAL SOCIETY CALIFORNIA RESEARCH CORPORATION SPACE TECHNOLOGY LABORATORIES NAVAL ORDNANCE TEST STATION 


\section{Pacific Journal of Mathematics}

\section{Vol. 12, No. $1 \quad$ January, 1962}

Jonathan L. Alperin, Groups with finitely many automorphisms $\ldots \ldots \ldots \ldots \ldots \ldots \ldots \ldots$

Martin Arthur Arkowitz, The generalized Whitehead product ................ 7

John D. Baum, Instability and asymptoticity in toplogical dynamics . . . . . . . . . . 25

William Aaron Beyer, Hausdorff dimension of level sets of some Rademacher series .... $\quad 35$

Frank Herbert Brownell, III, A note on Cook's wave-matrix theorem . . . . . . . . . . . . . 47

Gulbank D. Chakerian, An inequality for closed space curves ................. 53

Inge Futtrup Christensen, Some further extensions of a theorem of Marcinkiewicz ....... 59

Charles Vernon Coffman, Linear differential equations on cones in Banach spaces . . . . . 69

Eckford Cohen, Arithmetical notes. III. Certain equally distributed sets of integers . . . . . 77

John Irving Derr and Angus E. Taylor, Operators of meromorphic type with multiple poles

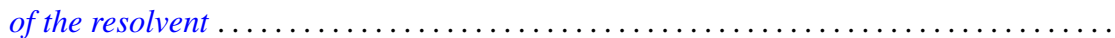

Jacob Feldman, On measurability of stochastic processes in products space .............

Robert S. Freeman, Closed extensions of the Laplace operator determined by a general class of boundary conditions, for unbounded regions ......................

Robert E. Fullerton, Geometric structure of absolute basis systems in a linear topological

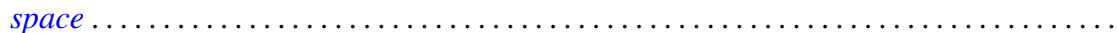

Dieter Gaier, On conformal mapping of nearly circular regions

Andrew Mattei Gleason and Hassler Whitney, The extension of linear functionals defined

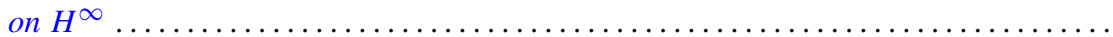

Seymour Goldberg, Closed linear operators and associated continuous linear

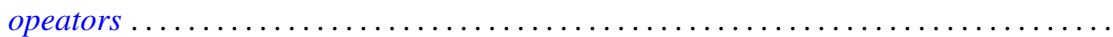

Basil Gordon, Aviezri Siegmund Fraenkel and Ernst Gabor Straus, On the determination of sets by the sets of sums of a certain order

Branko Grünbaum, The dimension of intersections of convex sets. .

Paul Daniel Hill, On the number of pure subgroups

Robert Peter Holten, Generalized Goursat problem . .

Alfred Horn, Eigenvalues of sums of Hermitian matrices ...........

Henry C. Howard, Oscillation and nonoscillation criteria for

$$
y^{\prime \prime}(x)+f(y(x)) p(x)=0
$$

Taqdir Husain, $S$-spaces and the open mapping theorem ...

Richard Eugene Isaac, Markov processes and unique stationary probability measures ...

John Rolfe Isbell, Supercomplete spaces ....................

John Rolfe Isbell, On finite-dimensional uniform spaces. II .........

N. Jacobson, A note on automorphisms of Lie algebras ..............

Antoni A. Kosinski, A theorem on families of acyclic sets and its applications

Marvin David Marcus and H. Minc, The invariance of symmetric functions of singular values...

Ralph David McWilliams, A note on weak sequential convergence.

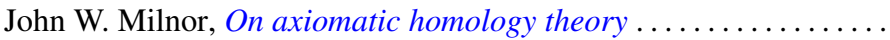

Victor Julius Mizel and Malempati Madhusudana Rao, Nonsymmetric projections in

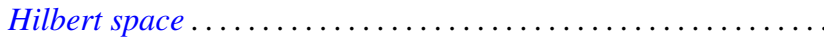

Calvin Cooper Moore, On the Frobenius reciprocity theorem for locally compact

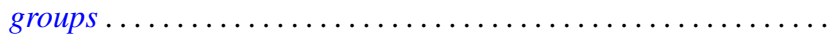

Donald J. Newman, The Gibbs phenomenon for Hausdorff means . 